\title{
Procalcitonin interest to assess a septic state inducing the death
}

\author{
Nouredine Sadeg ${ }^{1,2^{*}}$, Frédéric Tarlier ${ }^{3,4}$, Laurence Veneau ${ }^{3}$, Hafid Belhadj-Tahar $^{1}$ \\ ${ }^{1}$ Association Française de la Promotion de la Recherche Médicale (AFPreMed), Toulouse, France; \\ *Corresponding Author: nouredine.sadeg@ch-pontoise.fr \\ ${ }^{2}$ Laboratoire Claude Bernard, Centre Hospitalier René Dubos, Pontoise, France \\ ${ }^{3}$ Unité Médico-Judiciaire, Centre Hospitalier Emmanuel Rain, Gonesse, France \\ ${ }^{4}$ Service des Urgences-SMUR Centre Hospitalier Léon Binet, Provins, France \\ Received 25 March 2013; revised 30 April 2013; accepted 16 May 2013 \\ Copyright (C) 2013 Nouredine Sadeg et al. This is an open access article distributed under the Creative Commons Attribution License, \\ which permits unrestricted use, distribution, and reproduction in any medium, provided the original work is properly cited.
}

\section{ABSTRACT}

In this prospective study, we evaluated the use of PCT when collecting the body which was carried out. The chosen cut-off was set at 10 $\mathrm{ng} / \mathrm{mL}$ because at this level, the PCT was associated to a multiorgan failure attributable to a septic shock. For 90 cases, two groups were stratified by their final diagnosis: 33 of for non violent deaths and 57 of violent deaths. There was no significant elevation of procalcitonin rate (PCT) in the group of violent deaths. We noted 6 elevations of PCT rate above $10 \mathrm{ng} / \mathrm{mL}$ for non violent deaths (15.4\%) and in 3 cases there was an evidence for an infectious context (recent antiinfectious treatments, chemotherapy in progress). Control of CRP performed on blood samples found initial elevations above $10 \mathrm{mg} / \mathrm{L}$ in 3 of the 6 cases (including 2 of 3 cases associated with an infectious context). There is no evidence of PCT rate increase for intermediate PMI (post mortem interval), long PMI and undefined PMI. This study found a PPV (positive predictive value) and clinical specificity of $100 \%$ for a cutoff set at $10 \mathrm{ng} / \mathrm{mL}$. By taking this threshold, no significant PCT increase was observed in presence of death cases related to a violent origin as well as a fatal multi-organ failure due to malignant hyperthermia syndrome induced by neuroleptic use. The PCT appears to remain stable over time and whatever the conservation conditions of the body.

Keywords: Procalcitonin; Sepsis; Biomarker; Neuroleptic Malignant Syndrome

\section{INTRODUCTION}

In 2007, INSERM [1] reported, in France, 34703 deaths of unknown cause or ill-defined $(6.7 \%$ of all deaths). Thus, biomarkers are considered a useful tool to determine the cause of death in particular with suspect cause $[2,3]$. Sands reported in his study, a $2 \%$ rate of death due to sepsis occurred in academic tertiary care centers [4]. In this context the PCT, the 116 amino acid precursor of calcitonin, is a recognized marker of sepsis in clinical practice [5] and has also been validated in post-mortem analysis. Although, the postmortem PCT serum level remains similar to ante-mortem in the first 140 hours, body conservation condition could influence the behavior of this prohormone. The chosen cut-off is set at $10 \mathrm{ng} / \mathrm{mL}$. At this level, the PCT is associated with a multi-organ failure attributable to a septic shock. In this study, we evaluated the use of PCT when collecting the body carried out.

\section{METHODS}

We conducted a prospective study made in the Val d'Oise (France) by the forensic unit of the Gonesse hospital between January 2006 to January 2009. The sampling of whole blood in $\mathrm{NaF}$ as anticoagulant for the PCT assay was done from the collecting body when carried out. We have identified 96 cases and the state of conservation of their blood samples, allowed the measurement of PCT (samples were conserved at $-80^{\circ} \mathrm{C}$ ). PCT was assayed using an immunochromatography method (BRAHMS, GERMANY). We chose a cut-off of $10 \mathrm{ng} /$ $\mathrm{mL}$ as significant of septic state. The results were analyzed based on the post mortem interval (PMI) and the final diagnosis established. 


\section{RESULTS}

\subsection{As a Function of Post-Mortem Interval}

When PMI was short (1 to 12 hours; 8 cases), all PCT assays were negative ( $<$ to the cut-off). PMI was intermediate (12 to 24 hours) for 58 cases: 5 cases were found positive for the PCT $(8.6 \%)$ and accordingly to non violent deaths. In the group of long PMI (death after 24 hours), 5 cases showed negative PCT assays. Table 1 summarizes all the results.

In the long PMI group, the bodies were examined at the funeral. There is a positive assay (for a non violent death) among the 25 cases (4\%). There is no significant difference between the both ratios: groups short PMI/ intermediate PMI and intermediate PMI/long PMI. For 90 cases, two groups were stratified by their final diagnosis: 33 of non violent deaths and 57 of violent deaths. There was no significant elevation of PCT in the group of violent deaths for all PMI groups. We noted 6 elevations of PCT for non violent deaths (15.4\%) and in 3 cases there was an evidence for an infectious context (recent anti-infectious treatments, chemotherapy in progress). Control of C-reactive protein performed on blood samples found initial elevations above $100 \mathrm{mg} / \mathrm{L}$ in 3 of the 6 cases (including 2 of 3 cases associated with an infectious context). In a case of non violent death with negative PCT test with a short PMI and neuroleptic treatment, we found the temperature body abnormally elevated in regard to the PMI: these findings permitted to determine a probable neuroleptic malignant diagnostic.

\subsection{In the Context of Death}

For 90 data usable, two groups were defined from the cause of death established at the end of the lifting body with 33 non violent deaths and 57 violent deaths.

There was no significant elevation of PCT in the group of violent deaths. We note 6 elevations in PCT for non violent deaths $(15.4 \%)$. In three of these cases, it was found that during the removal of parts of the body, other parts evoke an infectious context (recent prescriptions and/or chemotherapy course).

\section{DISCUSSION}

The study Tsokos et al. [2] showed that the rate of

Table 1. PCT test PCT based on post mortem interval (PMI).

\begin{tabular}{ccc}
\hline & Negative PCT & Positive PCT \\
\hline Short PMI (liv-, Sti-) & 8 & 0 \\
Intermediate PMI (liv+, Sti+, Put-) & 53 & 5 \\
Long PMI (Put + ) & 5 & 0 \\
Funeral Examinations & 24 & 1 \\
\hline
\end{tabular}

Liv: lividity; Rig: Stiffness; Putrification: Put. post-mortem PCT were similar to ante-mortem rate in the first 140 hours. In this study, it is not highlighted increasing frequency of PCT positivity for long PMI, intermediate or if stored at the funeral home. PCT seems to remain stable over time and whatever the storage conditions of the body. However, given the size of some subgroups, it appears necessary to extend this analysis.

Ideally, the evaluation of any biomarker requires knowledge of the exact cause of death related to the completion of an autopsy. Under the prosecutor's decision, there are a number of deaths not suspicious when the etiology of death can not be known precisely at the end of the first findings of investigations. In 2007, INSERM [1] observed in France 34,703 deaths of unknown cause or ill-defined ( $6.7 \%$ of all deaths).

Using post-mortem of the PCT has been validated against a diagnosis ante-mortem known [2] or in the autopsy or forensic scientists [6]. This study found a positive predictive value (PPV) and a specificity of $100 \%$ for a threshold value of $10 \mathrm{ng} / \mathrm{mL}$ for PCT. By taking this limit, we do not find any significant increase in cases of violent death.

\section{CONCLUSION}

Use of the PCT as a biological marker for septic state is suitable in forensic science to explain the cause of death. As a part of the collection of the body, the existence of arguments in favor of a septic etiology in the initial findings may be supported by a significant rise in PCT. No significant PCT increase was observed in presence of death cases related to a violent origin as well as a fatal multi-organ failure due to malignant hyperthermia syndrome induced by neuroleptic use.

\section{REFERENCES}

[1] INSERM. Database on causes of death in France. http://www.cepidc.vesinet.fr

[2] Tsokos, M. Reichelt, U. Nierhaus, A. and Püschel, K. (2001) Serum Procalcitonin (PCT): A valuable parameter for the postmortem diagnosis of sepsis. International Journal of Legal Medicine, 114, 237-244. http://dx.doi.org/10.1007/s004140000177

[3] Belhadj-Tahar, H. Veneau, L. and Sadeg, N. (2008) Interest in forensic troponin Ic to a suspicious death. Canadian Society Forensic Science Journal, 41, 1-12.

[4] Sands, K.E., Bates, D.W., Lanken, P.N., Graman, P.S., Hibberd, P.L., Kahn, K.L., Parsonnet, J., Panzer, R., Orav, E.J., Snydman, D.R., Black, E., Schwartz, J.S., Moore, R., Johnson, B.L. and Platt, R. (1997) Epidemiology of sepsis syndrome in 8 academic medical centers. Journal of the American Medical Association, 278, 234-240. http://dx.doi.org/10.1001/jama.1997.03550030074038

[5] Belhadj-Tahar, H., Coulais, Y., Tafani, M. and Bouissou, F. (2008) Procalcitonin implication in renal cell apoptosis 
induced by acute pyelonephritis in children. Infection Drug Resistance, 1, 17-20.

http://dx.doi.org/10.2147/IDR.S3435

[6] Ramsthaler, F., Kettner, M., Mall, G. and Bratzke, H.
(2008) The use of rapid diagnosis test of Procalcitonin serum for the postmortem diagnosis of sepsis. Forensic Science International, 178, 139-145.

http://dx.doi.org/10.1016/j.forsciint.2008.03.010 